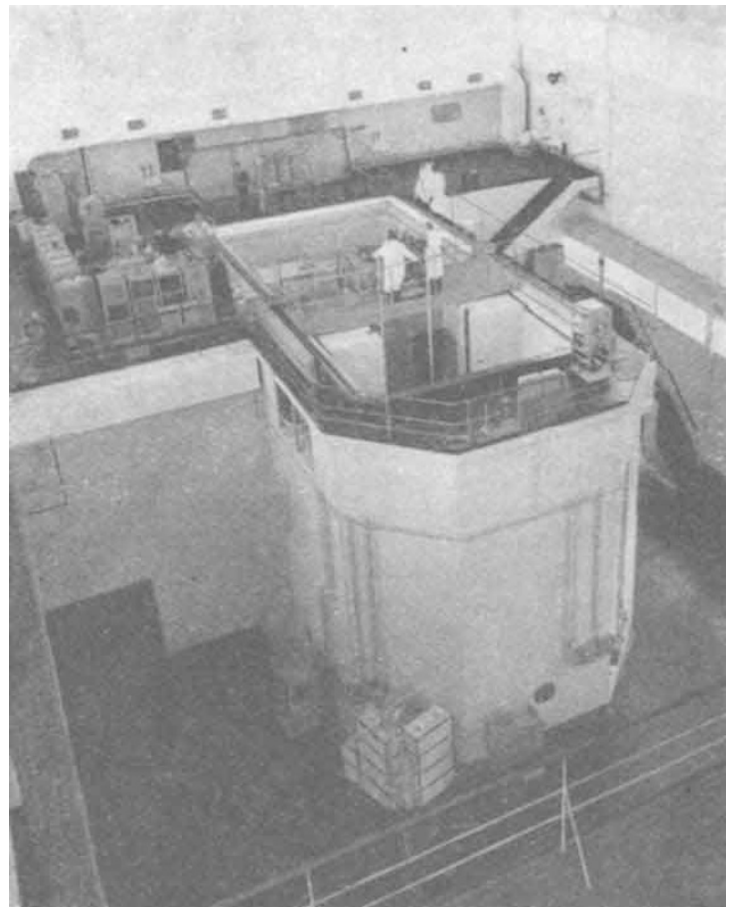

Fig. 2. Swimming pool reactor Mélusine tending this research into the range of $20-900^{\circ} \mathrm{K}$., and also the work of the neutron diffraction and magnetic resonance laboratories.

A radiochemistry laboratory has been installed in the Centre by the French Petroleum Institute, while the chemistry of solids laboratory is working on the production of a uranium compound for nuclear fuel elements.

There are, of course, also electronic laboratories, others for the study of applications of radioelements, and biology and nuclear physics laboratories, and also the thermal exchange laboratory, where heat exchanges with liquids in a reactor are studied.

The Centre's research programme is prepared by a scientific committee composed of six representatives from the Atomic Energy Commission and six professors from the University of Grenoble, who are scientific advisers to the Centre. This ensures the essential co-ordination with the programmes of other Atomic Energy Commission research centres.

As from January 1, the research work of the Centre is employing 300 persons. Construction is continuing, and the total staff by the end of 1961 will be 800 .

In order to help in obtaining the required number of staff, the Centre collaborates with the organizations entrusted with the training of technicians at all levels. It is also pleasant to note that the Centre is situated in a region that is both industrial and of tourist interest, in the heart of the French Alps, and therefore considered particularly attractive by young technicians.

\title{
OBITUARIES
}

\section{Prof. A. H. Gibson}

Prof. Arnold Hartley Gibson, emeritus professor of engineering in the University of Manchester, died on February 16 at the age of eighty.

Those who have read Prof. Gibson's monograph on Osborne Reynolds will realize how much 'A. H. G.' admired his own teacher. That he shared some of Reynolds's versatility is clear from the fact that although he will best be remembered for his contributions to hydraulics, he also did significant work in structures (the 'circular-arc bow girder') and in applied thermodynamics (many papers on internal combustion engines and heat transmission). At one period he was simultaneously a member of the Air Ministry Engine Research Committee and of the Severn Barrage Committee.

In hydraulics, his investigations ranged from the behaviour of bodies floating in vortices to river models; from water hammer in pipes to the effect of bridge piers on tides ; from centrifugal pumps to the interaction between passing vessels. His famous treatise "Hydraulics and its Applications" was published in 1908 ; the fifth edition appeared in 1952 : he was then seventy-four years old and told me how much he would have liked to rewrite it, but he feared that in that case the price would have been beyond the reach of many for whom the book was intended. The chapter on scale models which he added is probably his last published work.

His writings have an unfailing clarity and directness, virtues which were also very evident in the unaffected elegance of his lectures. He knew just when to stop before confusing the issue.
Gibson's reports on the Severn tidal model (1933) have rightly been described as 'monumental' (an adjective which caused him some amusement). The scope and variety of the experiments-the trials on bed materials, the introduction of silt and the representation of the coagulating effect of the salts of the sea, together with the study of the tides and the bore-remain unsurpassed in this field, even allowing for the later growth in the size of models. His investigations of the Severn and other estuaries revived British interest in the possibilities of scale models as an aid to the design of river and harbour works and led to the creation by the Department of Scientific and Industrial Research of the Hydraulies Research Station at Wallingford.

Generations of students have held him in affection as well as admiration, and one reason for this is to be found in his own interpretation of the duties of a professor. His aim was to inspire and never to 'spoon-feed'. He not only believed that he ought to lecture to each year but also he enjoyed doing so. The course of twenty or twenty-five lectures which he delivered to students in their first term at Manchester, covering a wide field of applied mechanies, brought immediate contact, and this was renewed in the second and third years. At one time or another he lectured on almost every subject in civil and mechanical engineering. Yet in addition he took his full share in the general work of the University in Senate, faculty and committees and maintained his output of important original papers.

The fact that he was able to do so much can be partly explained by his gift for making quick decisions. As Prof. J. A. L. Matheson has written 
elsewhere, "Gibson was a swift and brilliant intuitive worker. He could recognize a problem, build the apparatus, carry out the experiments and write up the results at a quite astonishing speed ....". He was equally happy in guiding and encouraging his colleagues and research students. When he saw you baffled, he would blow a ring of tobacco smoke and say, "If I were you, I would try . . .".

Gibson enjoyed good books (which he read with a speed like that of his own writing) and works of art. He detested the pompous and the shallow equally. He sought no honours, but those intimate with him saw that he was made happy and proud by such distinctions as the Ewing Medal of the Institution of Civil Engineers and the honorary degrees of LL.D. conferred upon him by St. Andrews and Manchester. It is probably true, however, that the D.Sc. which he won at Manchester fifty years ago remained his favourite.

Naturally, his name is linked most prominently with the Beyer chair in his Alma Mater (1920-49), but he spoke with great affection of his period in Dundee as professor of engineering in the University of St. Andrews (1909-20, interrupted by service during the First World War in the Army and at Farnborough).

Perhaps no truer or more fitting tribute could be paid to 'A. H. G.' by those of us who had the happy experience of being his students and colleagues than to say that we feel the same veneration for him as he felt for Osborne Reynolds. JACK ALLEN

\section{Prof. G. V. Douglas}

George Vibert Douglas died suddenly in Toronto, Canada, on October 8, 1958, at the age of sixty-six. From 1932 until his retirement in 1957 he was Carnegie professor of geology at Dalhousie University in Halifax, Nova Scotia.
Prof. Douglas was born in Montreal in 1892. At McGill University he studied under F. D. Adams, but this training was interrupted by the First World War and he went overseas in 1915. He served in France and Flanders with the 17th Battn. Northumberland Fusiliers and, for a short time, with the Royal Engineers. He was awarded the Military Cross and mentioned in dispatches. He returned to Canada in 1919. He graduated from McGill in 1920 and received his M.Sc. degree in 1921 .

$\mathrm{He}$ spent the next two years in the Antarctic as geologist with Shackleton's last expedition. While working up the results of the expedition, he was able to work in the University of Cambridge. This was followed by further work at Harvard University, where he held a part-time post as instructor under Daly. In 1926, he became chief geologist for the Rio Tinto Company -at first in Spain and later on the Rhodesian Congo Border concession. In 1932 he left the Rio Tinto Company to take up the post at Dalhousie which he held for the remainder of his active life.

Prof. Douglas was a notable factor in the lives of a whole generation of students. Undoubtedly his greatest influence arose from his ability to inspire enthusiasm and to encourage the student to do the best of which he was capable. A secondary influence was his own wide-ranging interest, and one recalls vividly the stimulus of an afternoon at his home, when ideas (some good, many otherwise, no doubt) flew like shuttlecocks as the teacher encouraged his students to exercise their wits. Ideas strongly held often plunged him into controversy but, though many disagreed, there were none who did not admit his courage and integrity.

$\mathrm{He}$ is survived by his wife, two daughter's and two sons, and by his sister, Dr. A. V. Douglas, of the Department of Astronomy, Queen's University, Kingston, Ontario.

\section{NEW FELLOWS OF THE ROYAL SOCIETY}

A ' $\mathrm{I}$ a meeting of the Royal Society on March 19, A the following were elected to fellowship of the Society :

Dr. G. H. Beale, senior lecturer in genetics in the University of Edinburgh (Institute of Animal Genetics), distinguished for his researches on the genetics of flower pigments and on nucleus-cytoplasm relations in Paramecium.

Prof. F. Bergel, professor of chemistry in the University of London, at the Chester Beatty Research Institute of the Institute of Cancer Research, Royal Cancer Hospital, distinguished for his work in synthetical organic chemistry in the field of vitamins and drugs.

Dr. Ann Bishop, director of the Medical Research Council Group for Research in Chemotherapy, at the Molteno Institute of Biology and Parasitology, Cambridge, distinguished as a protozoologist and especially for her work on the malaria parasite and its resistance to drugs.

Prof. G. E. Blackman, Sibthorpian professor of rural economy in the University of Oxford (Department of Agriculture), distinguished for his research work on the ecology of wild and cultivated plants and on weed-killers.
Prof. H. Bondr, professor of applied mathematics in the University of London (King's College), distinguished for his contributions to cosmology, astrophysics and other branches of theoretical physics.

PRof. J. M. CASSELS, professor of experimental physics in the University of Liverpool, distinguished for his studies of high-energy nuclear physics using particle-accelerating machines.

Prof. A. R. Clapham, professor of botany in the University of Sheffield, distinguished for his research upon many important aspects of ecology and taxonomy, especially those relating to British plants.

DR. F. H. C. CRICK, member of the staff of the Medical Research Council Unit for Research on the Molecular Structure of Biological Systems at the Cavendish Laboratory, Cambridge, distinguished for his contributions to molecular biology.

Mr. G. B. R. Femlen, director of research. Ruston and Hornsby, Ltd, Lincoln, distinguished for his application of scientific principles to the development and design of industrial gas turbines.

Dr. D. W. W. Henderson, director of the Ministry of Supply Microbiological Research Establishment, 